\title{
Hospital Location Selection: A Systematic Literature Review on Methodologies and Applications
}

\author{
Muhammet Gul $\mathbb{D}^{1}$ and Ali Fuat Guneri $\mathbb{D}^{2}$ \\ ${ }^{1}$ Munzur University, Department of Emergency Aid and Disaster Management, Tunceli, Turkey \\ ${ }^{2}$ Yildiz Technical University, Department of Industrial Engineering, Istanbul, Turkey
}

Correspondence should be addressed to Muhammet Gul; muhammetgul@munzur.edu.tr

Received 13 October 2020; Revised 2 February 2021; Accepted 6 February 2021; Published 13 February 2021

Academic Editor: Gordon Huang

Copyright (c) 2021 Muhammet Gul and Ali Fuat Guneri. This is an open access article distributed under the Creative Commons Attribution License, which permits unrestricted use, distribution, and reproduction in any medium, provided the original work is properly cited.

\begin{abstract}
The increased focus of people on the quality of health care in recent years has led hospital owners to develop strategies and policies to improve medical services through the establishment of new hospitals. For hospitals to be competitive, the hospital's location and proximity to potential patients are considered crucial factors in establishing new hospitals. In this context, evaluating and selecting the most suitable hospital location to establish a new hospital from the multicriteria decision-making (MCDM) perspective is a priority for the entrepreneurs or government to gain a competitive advantage. Therefore, this study aims to present a systematic literature review of the hospital location selection problem considering the applied methods and application areas. The preferred reporting items for systematic review and meta-analysis statement (PRISMA) are used as a reference framework. Initially, known electronic databases (Web of science, IEEEXplore, Scopus, Science direct, and Google Scholar) were searched up to the early 2021. A number of 47 articles are selected and analyzed under this systematic framework based on inclusion-exclusion points. State-of-the-art developments in adopting MCDM methods and their fuzzy extensions are summarized. All the articles have been examined in a systematic taxonomy to find answers to six research questions (trend, country of origin, outlet journal, MCDM methods used, MCDM environment and criteria type, and decision criteria used). Results show that (1) AHP and GISbased MCDM models are the most contributing approaches to the solution of this problem, (2) location selection criteria are mostly cost, demand, environment, population, government, competition in the market, and distance to some important places, (3) the fuzzy structure is also preferred in addition to the MCDM structure depending on the crisp data type, and (4) the location selection criteria are mostly considered subjective. We pay attention to promising directions that can dominate future research in this field from a methodological or applicability perspective. This study shows the current views and opportunities for researchers and practitioners and acts as a guide to encourage more creative studies in this field.
\end{abstract}

\section{Introduction}

The decision to choose a hospital location is one of the most crucial policy decisions that government and health policymakers pay attention to. In health care, the priority is to give all patients the right place and exemplary service and be fair. Choosing the optimal hospital location is vital for the effectiveness, quality, and equity of health services [1]. The choice of hospital location is a strategic decision [2]. The location to be selected should be sustainable and capable of eliminating future problems. Choosing the wrong location can lead to significant customer dissatisfaction and increase in cost [3]. A vivid example of this situation is the Covid-19 pandemic.

Nowadays, an overwhelming majority of the world is still fighting against this pandemic. The world has faced an unusual demand for infected people in hospitals. This surge made it mandatory for countries to build hospitals, field hospitals, or specific pandemic hospitals in a considerable and short time. Initially, the Chinese government has recently announced that the two hospitals in Wuhan were built within ten days to meet increased demand. Many other countries, like Turkey, have decided to do so in 45 days. These unpredictable conditions have obliged states to make 
these investments and make these decisions that cover various criteria. Therefore, many criteria should be considered in a suitable location selection process. This problem depends on many criteria such as environment, demand, population, proximity, competition, government policies, and costs as in other hospital ranking problems [4-8]. For this reason, the selection of a hospital location can be considered as a multicriteria decision-making (MCDM) problem [1].

The problem can be regulated by employing a carrying capacity model, GIS, MCDM, or fuzzy models. MCDM methods have been widely applied to this subject. One of the most applied methods is AHP [1]. Other applied methods are ANP, TOPSIS, VIKOR, ELECTRE, SAW, GRA, EDAS, ARAS-G, CODAS, CRITIC, Entropy, and fuzzy extensions of these methods. There is an MCDM method specific to each heading (the stage in hospital location selection). For example, pairwise comparison-based MCDM methods are the most widely used method for determining criterion relative importance levels. This is because the relevant stage of the problem shows full compliance with the structure of the method. Figure 1 illustrates the problem's implementation stages with the relevant tools for each stage.

Since the topic is handled in many types of research, there is no review paper covering state-of-the-art research. The only attempt by Moradian et al. [9] aims to determine disaster risk criteria in hospital location selection by criticizing 15 studies. They have merely categorized the criteria without reviewing the methods, criteria type, uncertainty analysis in data type, and some various aspects (publication trend, country of origin, and publication outlet either as a journal article or known conference paper). Moradian et al. [9] stated that there exist two crucial theories in hospital location analysis. While one is the Weberian model, which focuses on a single objective, namely, the minimum cost or maximum profit, the second is concerned with the "behavioral approach" which simultaneously considers numerous criteria to determine the most suitable location. MCDM-based methods are considered under this second theory. Since the literature lacks in terms of presenting studies of hospital location selection from the MCDM perspective, we aim to provide a state-ofthe-art literature review of the hospital location selection problem considering the applied MCDM methods and selection criteria. Known electronic databases were searched up to the early 2021 with the aid of the PRISMA framework. Articles that orient various MCDM methods are selected and analyzed under a systematic framework. State-of-the-art developments in adopting MCDM methods and their fuzzy extensions are summarized in a hospital location selection process. We pay attention to promising directions that can dominate future research in this field from a methodological or applicability perspective. This study is different from the Moradian et al. [9] study by providing a general criteria hierarchy that can be fitted to the possible future hospital location selection research. The existing literature review also reveals the gaps in fuzzy MCDM domain that researchers can benefit from in hospital location selection studies.
In summary, to the best of the authors' knowledge, although there are different state-of-the art reviews on location selection problem in the literature [10-15], there is no review paper attempt regarding hospital location selection. As a result, to fill the gap in the literature, we provide a systematic review of publications related to hospital location selection till 2020 with focusing on MCDM concept and the state-of-the-art progress in this subject. Contrasted with the existing reviews on similar subjects, the novelties of this review are as follows: (1) we focus on the problem from the MCDM perspective and as well as GIS tools; (2) we categorize the applied methods, the decision criteria, MCDM environment, and type of criteria by reviewing the publications in detail; and (3) we highlight the advantages and disadvantages of applied methods as well as research limitations, and future research studies are determined.

The rest of the paper is organized as follows. The second section gives the literature reviewing methodology. Then, in the third section, we provide the results in graphs and tables. The last section offers future research areas that can be studied by scholars.

\section{Review Methodology}

A PRISMA framework is frequently used in the literature [16-23] which is followed as the review methodology of this study. The referenced review studies have considered the following issues in designing their review frameworks: (1) search strategy, (2) inclusion-exclusion criteria, (3) study selection, and (4) data extraction and classification. Initially, known electronic databases (Web of science, IEEEXplore, Scopus, Science direct and Google Scholar) were scanned until the early 2021 by using suitable keywords. In this study, a Boolean query search using keywords such as "hospital location selection" OR "hospital site selection" OR "MCDM" OR "GIS" OR "AHP" OR "TOPSIS" is used. Also, the search is executed by different combinations of these keywords and as well as their long versions (e.g., multicriteria decision-making, geographical information system, analytic hierarchy process, and technique for order preference by similarity to ideal solutions). A total of 40 pages were scanned in Google Scholar with these key terms and the famous databases of WOS, IEEEXplore, Scopus, and Science direct. Here, to add Google Scholar as an outlet in our search, many studies regarding our scope are not included in the essential databases. A considerable amount of articles on hospital location/site selection were unfortunately published in journals not included in SCIExpanded, SCI, SSCI, or ESCI indexes. For this reason, we have scanned Google Scholar to a certain number of pages. The inclusion criteria are that the article is written in English and is a journal or important conference article (e.g., IFAC, IEEE, or ASCE).

Studies with the following criteria are excluded within this review: (1) the location of the hospital is directly determined with a conceptual framework without using any mathematical model or MCDM-based model; (2) it has handled the location problem of any nonhospital health- 


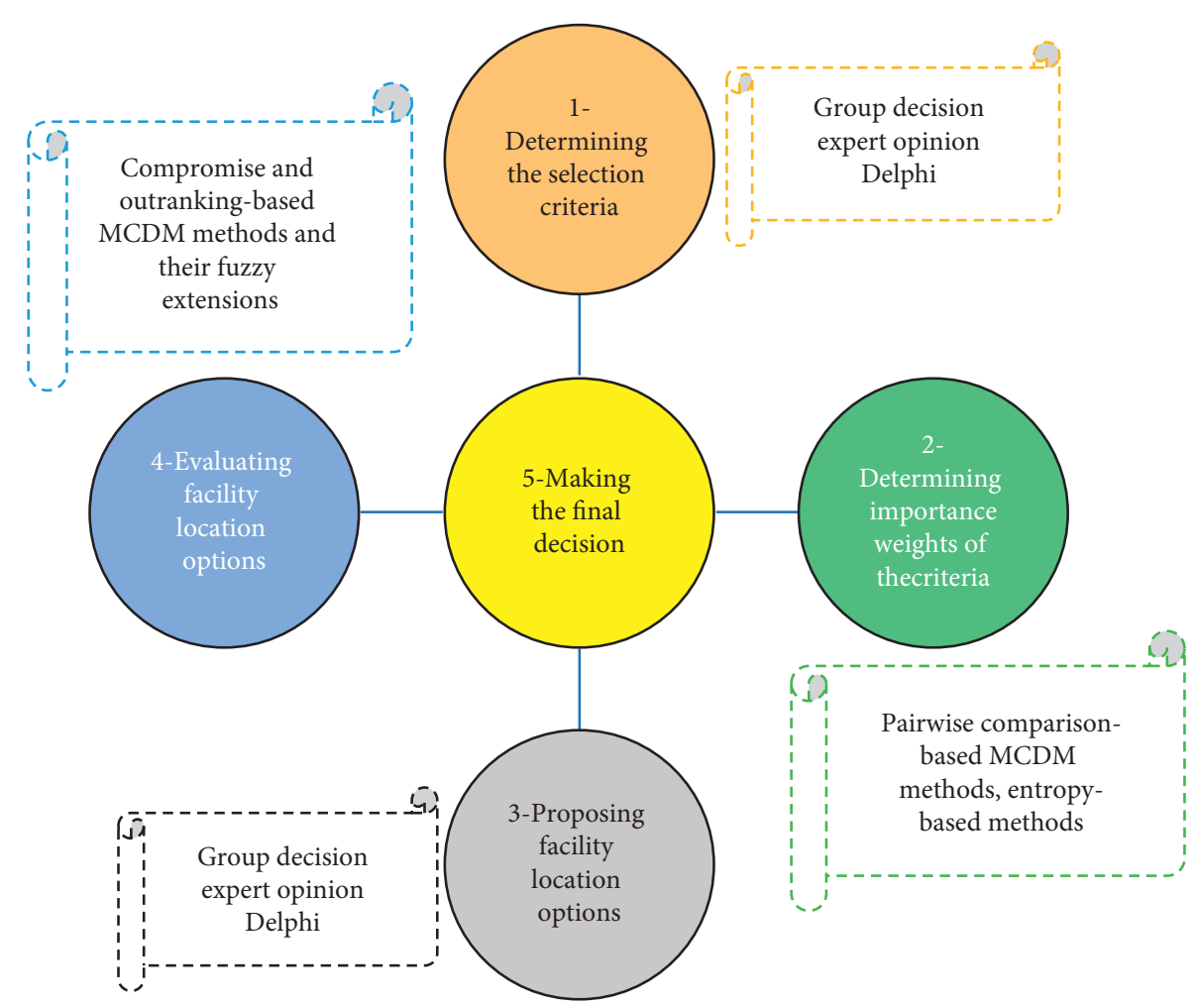

Figure 1: The implementation stages of the problem with the methods used in each stage.

related facility; (3) the writing language of the article is not English (e.g., Arabic); and (4) the study is a review article, not a research article. After extracting duplicate articles in each database, the articles' titles and abstracts were scanned according to the inclusion/exclusion criteria. At this stage, the articles that appeared out of the subject were sorted out. In the PRISMA eligibility assessment phase, among 49 papers, one paper was excluded [24] since its writing language is Arabic. One another paper [9] seems not a research article. Therefore, we exclude it from the current paper pool. Finally, we structured our state-of-the-art review by including 47 papers (Figure 2). Some essential topics were collected on an Excel sheet to discuss hospital location selection. The column names in this sheet are as follows: Study ID, Study abbreviation (in the format of First author last name et al. [Publication year]), Year of publication, Country of origin, Journal name, Applied method(s), MCDM environment, Type of fuzzy set (e.g., fuzzy, crisp, and rule-based), Type of criteria (subjective, objective, and subjective + objective), and Main criteria. We then carry out some analyses in the light of the reviewed studies. These headings also show the content of the research questions (RQs) that the article seeks to answer. These RQs were identified, and answers were sought. The RQs determined for the analysis are as follows:

(i) RQ1: How is the trend in hospital location selection papers?

(ii) RQ2: What are the country of origin for the performed hospital location selection study?

(iii) RQ3: In which journals they are published? (iv) RQ4: Which MCDM methods are used?

(v) RQ5: Which MCDM environment and type of criteria are used?

(vi) RQ6: Which main criteria are preferred in these studies?

\section{Results}

This section presents the distribution of papers by the following points of view: (1) publication trend by years, (2) distribution of in terms of country of origin, (3) published journal, (4) applied MCDM methods either in single or hybrid, (5) MCDM environment and type of criteria used in the papers, and (6) the location selection criteria used in the documents.

3.1. Publication Trend. Firstly, the time-dependent variation of the number of papers included in this literature review has been handled. Figure 3 shows the trend of articles by year. It can be easily seen that there are two crucial outliers in the production of papers in 2013 and 2016. The exponential trend has an acceptable $R^{2}$ value (40\%), indicating that the documents increase through the literature.

3.2. Country of Origin for the Hospital Location Selection Studies. Secondarily, the reviewed papers are analyzed by country of origin. The "country of origin" criterion we examine here refers to the country of the first author of the reviewed study. Figure 4 demonstrates the classification with 14 portions. Turkey accounts for almost $13(28 \%)$ of all 


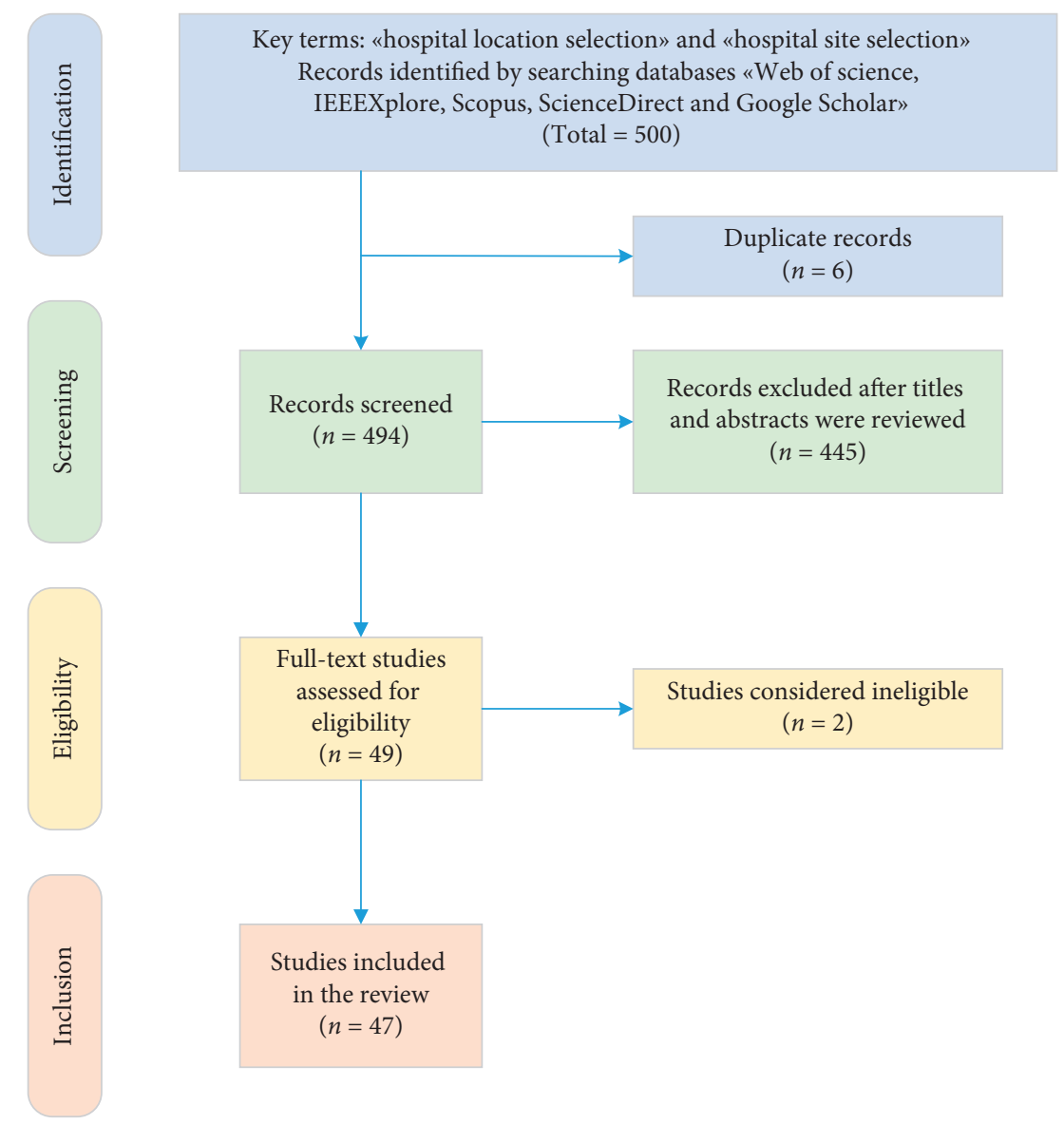

FIGURE 2: Flow chart of the literature review methodology on hospital location selection.

papers. Iran and Taiwan are also prolific in hospital location selection models $(10 ; 21 \%, 6 ; 13 \%)$. The remaining countries have a rather testimonial presence (USA, Australia, Bangladesh, China, Egypt, India, Iraq, Italy, Malaysia, Palestine, and Chile).

3.3. Publishing Journal Distribution. Thirdly, the distribution of articles is analyzed in terms of published journals. Most of the journals have one entry ( $93 \%, n=44 / 47$ papers). There are only four conference proceeding papers published in IEEE, ASCE, and IFAC conferences. Expert Systems with Applications, Health Policy and Technology, International Journal of Healthcare Management, International Journal of Information Technology \& Decision-Making, Journal of Management Analytics, Land Use Policy, Quality \& Quantity, Sustainability, The Journal of Grey Systems, and Building and Environment are some of the famous indexed-based journals (such as Science Citation Index, Science Citation Index Expanded, and Emerging Sources Citation Index.) in which the reviewed hospital location selection papers are published.

3.4. Applied MCDM Methods and Their Extensions. From the point of applied MCDM methods, the following significant findings can be extracted (Table 1). (1) AHP and GIS-based models play a dominant role among all methods $(n=18 / 47)$. Among these 18 papers, five studies integrated AHP and GIS in selection. (2) Higher than half of the published papers utilize a hybrid MCDM approach. ANP-TOPSIS and FTOPSIS are forefronts. (3) Some well-known MCDM methods are not used in the reviewed papers anymore, for example, methods like BWM, PROMETHEE, DEMATEL, and MAIRCA. (4) In hybrid approaches, GIS is the most frequently preferred tool as it can visually analyze location. It is often used in other location selection problems.

AHP is a common MCDM method that has previously been applied to various problems in location selection. It has some characteristic features. It has a decision hierarchy that demonstrates the difficulty in levels. These levels include decision goals, criteria, subcriteria, and alternatives. The method is also based on a pairwise comparison manner using the 9-point scale of Saaty. It checks the consistency of decision matrices to build the model on a factual basis. The problem of hospital location selection can be easily solved via AHP and its improvements. This problem has a decision hierarchy, which the AHP method also has. The usage of AHP and GIS in hospital location selection problems stems from their advantages and integration compatibility. A GIS is a visual tool that provides convenience in understanding the criteria of the potential location such as geographic, geological, and distance to central points [25-32]. It also 


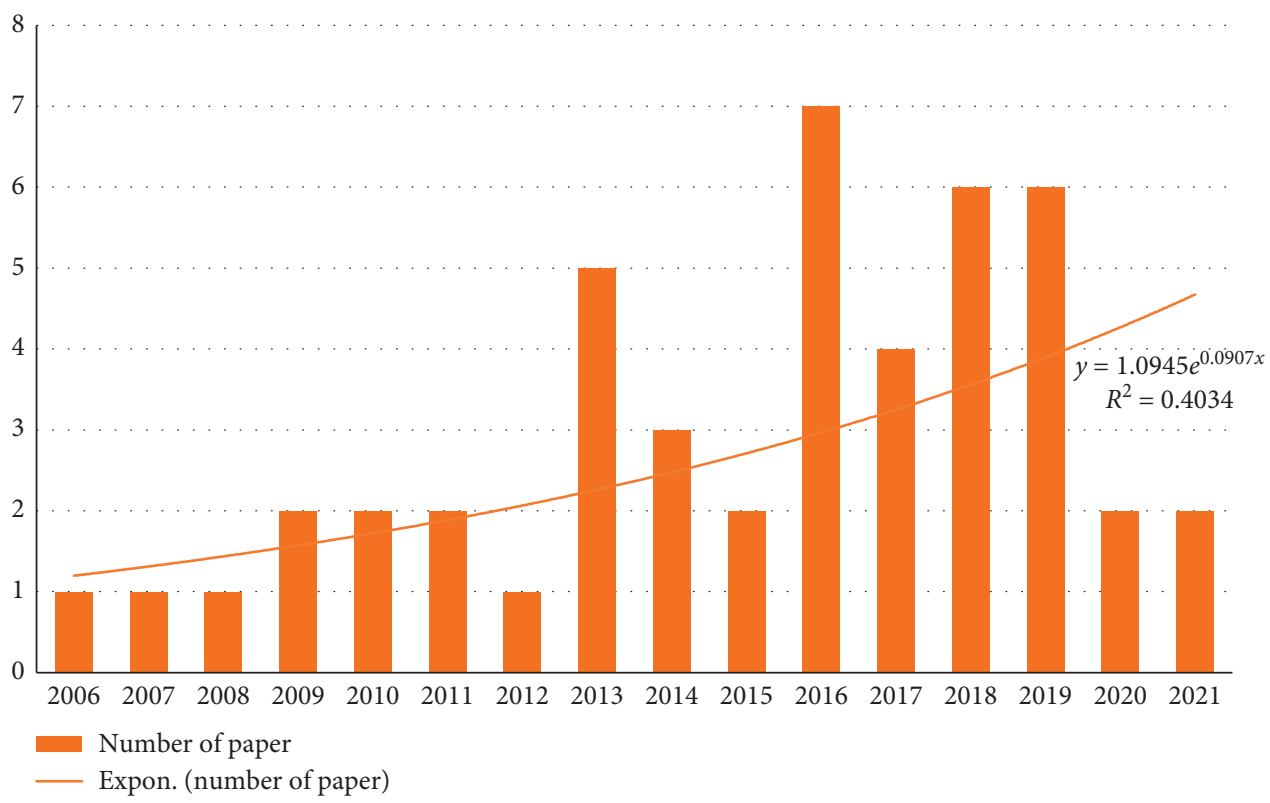

FIgURE 3: Trend of the papers by year.

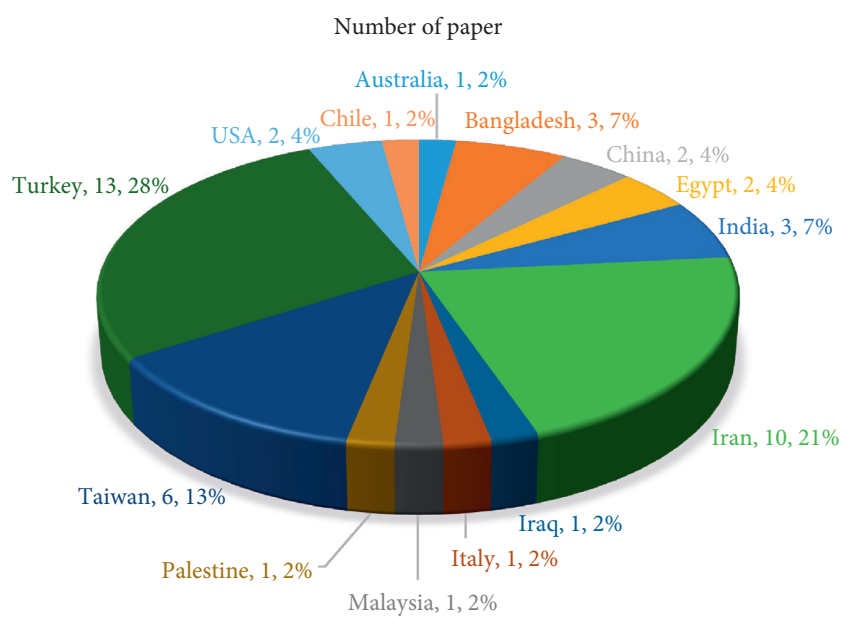

FIgURE 4: Distribution of papers in terms of country of origin.

includes many useful maps with various layers. Apart from GIS modeling, AHP is combined with other MCDM methods in hospital location selection. Among these methods, TOPSIS and its derivations are forefronts [2, 33-39]. The TOPSIS method was initially proposed by Yoon and Hwang [40] as an MCDM method. It is based on separation from the ideal and negative-ideal solution concept. According to the method, each evaluation criterion has a monotonous increasing or decreasing trend. To create an ideal solution, the largest of the weighted evaluation criteria in the matrix is selected [41]. It uses a criteria weight matrix and a decision matrix consisting of alternatives, criteria, and respected performance measures. In Khaksefidi and Miri [36], the final scores of three MCDM methods (TOPSIS, ELECTRE, and SAW) are compared. Four of the reviewed studies integrated various fuzzy set theory versions with
TABLE 1: Distribution of papers in terms of applied single or hybrid MCDM method(s) and GIS tool.

\begin{tabular}{|c|c|c|}
\hline Method (single or hybrid) & $\begin{array}{c}\text { Number of } \\
\text { paper }\end{array}$ & $\begin{array}{c}\text { Percentage } \\
(\%)\end{array}$ \\
\hline AHP & 6 & 13.04 \\
\hline GIS & 6 & 13.04 \\
\hline GIS, AHP & 5 & 10.87 \\
\hline ANP, TOPSIS & 2 & 4.35 \\
\hline F-TOPSIS & 2 & 4.35 \\
\hline AHP, GRA & 1 & 2.17 \\
\hline $\begin{array}{l}\text { AHP, TOPSIS, ELECTRE, } \\
\text { SAW }\end{array}$ & 1 & 2.17 \\
\hline ANP & 1 & 2.17 \\
\hline ARAS-G & 1 & 2.17 \\
\hline Belief rule-based & 1 & 2.17 \\
\hline D-AHP, DF-AHP & 1 & 2.17 \\
\hline Evidential reasoning & 1 & 2.17 \\
\hline F-ANP & 1 & 2.17 \\
\hline F-ELECTRE & 1 & 2.17 \\
\hline F-MCDM & 1 & 2.17 \\
\hline F-SAW & 1 & 2.17 \\
\hline GIS, ABM & 1 & 2.17 \\
\hline GIS, AHP, ANN & 1 & 2.17 \\
\hline GIS, F-AHP & 1 & 2.17 \\
\hline GIS, F-AHP, F-ANP & 1 & 2.17 \\
\hline GRA & 1 & 2.17 \\
\hline GRA, Entropy & 1 & 2.17 \\
\hline HF-TOPSIS & 1 & 2.17 \\
\hline P-CNP, AHP & 1 & 2.17 \\
\hline SF-TOPSIS & 1 & 2.17 \\
\hline $\begin{array}{l}\text { TOPSIS, EDAS, CODAS, } \\
\text { CRITIC }\end{array}$ & 1 & 2.17 \\
\hline VIKOR & 1 & 2.17 \\
\hline CRITIC & 1 & 2.17 \\
\hline CRITIC, CoCoSo & 1 & 2.17 \\
\hline $\begin{array}{l}\text { GIS, ANP, CRITIC, EDAS, } \\
\text { VIKOR }\end{array}$ & 1 & 2.17 \\
\hline
\end{tabular}


TOPSIS in evaluating alternative hospital locations [2, 34, 35, 39]. While Miç and Antmen [2] and Baran [34] applied for fuzzy triangular numbers in TOPSIS, Kahraman et al. [35] and Senvar et al. [39] used spherical fuzzy numbers and hesitant fuzzy numbers, respectively, in TOPSIS. Kutlu Gündoğdu and Kahraman [35] proposed that spherical fuzzy sets reflect uncertainty and ambiguity in real-world decision problems better than classical fuzzy set theory. They are mathematically based on a membership function on a spherical surface. They independently describe the degree of membership, nonmembership, and hesitancy in a larger domain (the sum of these three values must be between 0 and 1). They are considered as the integration of Pythagorean fuzzy sets and neutrosophic sets. Hesitant fuzzy sets have a flexible style in dealing with uncertainty by allowing many potential degrees of membership of an element to a set. Considering the advantages of these fuzzy sets, an improved TOPSIS model can pay more attention to the hospital location selection problem. There are still more gaps in the literature regarding this problem using new types of fuzzy set theory. The neutrosophic fuzzy set, Pythagorean fuzzy set, Fermatean fuzzy set, intuitionistic fuzzy set, and interval type-2 fuzzy set are not integrated with TOPSIS. However, they can easily produce reasonable solutions in solving the hospital location selection problem. Lin and Tsai [38] and Lin and Tsai [37] developed an ANP-TOPSIS integrated model where ANP is used to obtain relative location selection criteria weights apart from AHP-TOPSIS models.

There are also some single and hybrid MCDM methods applied to the hospital location selection. Single methods refer to a single MCDM method without merged with any fuzzy set extension. For example, ANP is used by Önüt et al. [42]. They improved the study of Wu et al. [43] by modifying location selection criteria considering the observed country's local conditions. This study is followed by two studies focusing on single GRA methods and VIKOR, respectively $[44,45]$. In a study by Lin et al. [45], an optimal location for a regional Taiwanese hospital location is determined via the GRA-based model. Wang et al. [46] proposed a model for selection of hospital constructions with probabilistic linguistic MCDM with weight determined by the CRITIC method. Çelikbilek [44] evaluated to select the best hospital location for a private health institution using VIKOR. VIKOR is originally in Serbian (VlseKriterijumska Optimizacija I Kompromisno Resenje) and means that multicriteria optimization and compromise solution. It was initially proposed by Opricovic [47]. It requires a criteria weight matrix and a decision matrix covering alternatives, criteria, and respected performance measures (values of alternatives concerning the criteria). From this aspect, it provides useful solutions to the problems suitable for the MCDM concept. Although it has not contributed a lot to the hospital location selection problems [48], it can solve this problem with its compromised solution concept like TOPSIS.

On the other hand, hybrid methods refer to an MCDM method, often equipped with different fuzzy sets. FELECTRE [49], F-SAW [50], and F-ANP [51] are some examples from the reviewed papers. The ARAS-G proposed in Sen [52] puts the ARAS method and grey numbers together to determine a new public hospital location. In a study by Hashemkhani Zolfani et al. [53], a grey-based decision support framework using CRITIC and CoCoSo methods for location selection of a temporary hospital for Covid-19 patients is used. A case study is also performed for Istanbul using the proposed decision-making framework.

In most of the reviewed papers, AHP and its extensions (e.g., F-AHP, D-AHP, and DF-AHP) and some similar methods (e.g., entropy, ANP, and F-ANP) are used to obtain relative importance values (weights) of location selection criteria and subcriteria $[3,42,51,54-56]$. However, new and novel approaches have been recently released in the literature to overcome the drawbacks of AHP. The best example that comes to mind quickly is BWM. It is a recently proposed MCDM method by Rezaei [57]. It needs a smaller number of pairwise comparisons and more consistent comparisons compared with AHP. Since the crisp values of criteria may be inadequate to model, the problem considering the vagueness and ambiguity and providing pairwise comparisons with less compared data, the BWM is extended with fuzzy triangular sets [58]. The method is applied in various areas from manufacturing to supply chain management and transportation [59-61]. Although plenty of research studies are performed in these areas, there is no contribution to hospital location selection analysis.

Various methods are applied to the hospital location selection problem like belief rule-based system and evidential reasoning $[62,63]$. The evidential reasoning method is developed to handle MCDM problems having both qualitative and quantitative criteria. Unlike classical MCDM methods, it demonstrates the MCDM problem via a decision matrix (in another name, a belief expression matrix). Each decision criterion regarding hospital location selection concerning alternative locations is described by a distribution assessment using a belief structure [62]. Therefore, evidential reasoning is well-suited to handle incomplete uncertainty since it uses a belief structure to model an assessment as a distribution [63]. Apart from these, in a study by Kaveh et al. [28], two important metaheuristics algorithms "GA and PSO" are used with AHP and GIS in a hospital location-allocation problem.

3.5. MCDM Environment and Type of Criteria. Another vital highlight included in the literature analysis is the MCDM environment and the type of decision criteria. Crisp, fuzzy, and grey environments are considered under the MCDM environment. There are also a limited number of studies using rule-based systems or knowledge-based systems. According to Figure 5, twenty of the studies have crisp MCDM environment; twelve studies use fuzzy numbers $[2,3,34,35,39,44,49-51,55,56,64]$, two of them apply grey $[46,52,65]$ and rule-based structure $[62,66]$, one study [63] is in a knowledge-based structure, and the rest are nonapplicable (n/a) within the scope.

Regarding the fuzzy set version used in the hospital location selection problem, we can say that fuzzy triangular numbers are the most preferred. In 10 of the 12 studies, fuzzy 


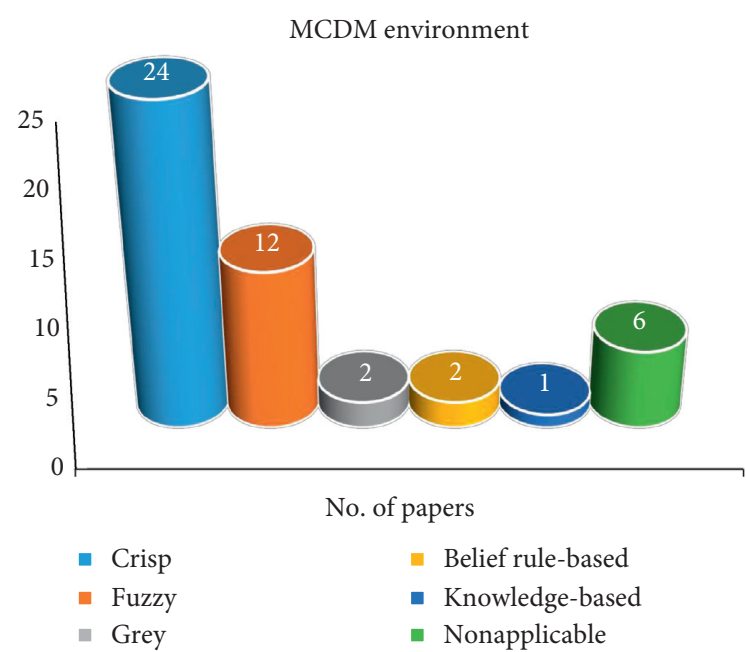

Figure 5: Distribution of papers in terms of MCDM environment.

triangular numbers $[2,3,34,44,49-51,55,56,64]$ were used, while spherical fuzzy numbers [35] were used in one and hesitant fuzzy numbers [39] in one. To illustrate the advantages of joint usage of MCDM and fuzzy sets in hospital location selection, a comparative discussion of the classical MCDM, grey theory-based MCDM, and general fuzzy set theory-based MCDM techniques is performed and presented in Table 2. The classical MCDM does not consider data/information uncertainty, converting experts' judgments into a crisp value. The grey theory-based MCDM and general fuzzy set theory-based MCDM reflect the uncertainty of experts' assessment environment. Still, they do not measure the degree of membership and nonmembership of the evaluated events simultaneously.

Another critical issue in the examined studies is the type of location selection criteria data used (Figure 6). We made a classification as subjective, objective, studies using both, and nonapplicable ones. While 32 out of 47 studies dealt with the criteria subjectively, 6 of them use both subjective and objective criteria $[25,29,33,50,62,67]$ and one of them use only objective criteria [37].

3.6. Selection Criteria Used for Hospital Location. The hospital location selection is defined by the implementation of a five-stage process which is divided into the following headings $[1,9,64]$ :

(i) Determining the selection criteria

(ii) Determining the importance of these criteria

(iii) Proposing facility location options

(iv) Evaluating facility location options

(v) Making the final decision

As one of the main components of this problem is the decision criteria, it is so crucial to discuss the papers in terms of selection criteria in depth. The reviewed papers' decision criteria are analyzed (please refer to Table 3 to see the whole list of main criteria used in selecting hospital location). According to the results, nearly half of the papers $(n=20 / 42)$ utilized a "cost" related main criterion. It is mentioned with a name of investment costs, travel costs, construction costs, land cost, building regulation cost, and merely cost in different studies. In 10 papers, demand is mentioned as the main criterion. 18 of 42 papers include a main environmental criterion. It is mentioned in various names such as "Environmental factors," "Environmental situation," "Environmental quality," "Environment," "Environment and safety," "Environmental issues," and "Environmental favor." In 11 papers, the population is also considered as a crucial parameter on hospital location selection. Seven studies focus on competition on the market and distance to some critical locations.

The first two studies on hospital location selection are described by Lin et al. [45] and Wu et al. [43]. In these two studies, six main criteria were determined: (1) factor conditions, (2) demand conditions, (3) firm strategy, structure, and rivalry, (4) related and supporting sectors, (5) government, and (6) chance. In the factor conditions criteria group, authors consider capital cost, labor cost, and land use cost as subcriteria. Capital cost refers to the capital to construct a hospital building [43]. Labor costs cover the costs to be spent on staff, including doctors, nurses, technicians, pharmacists, caregivers, cleaning staff, and all other healthcare professionals regarding quality and quantity [39]. Land use cost is described as an economic value and suitability of land for constructing a hospital building. For example, the cost may vary depending on whether the land is arid or commercial land $[29,43,76]$. Some scholars have used different names concerning this group (factor conditions). These are as follows: In the studies of Miç and Antmen [2], Baran [34], Lin et al. [50], and İnce et al. [74], "an investment cost" term is mentioned to define a total of hiring purchase, facility arrangement costs, and environmental planning costs. Kahraman et al. [35] used the term "installation costs" instead of factor conditions. Almost half of the scholars mention a general term of "cost" in the context of factor conditions group $[2,3,26,33-35$, $39,44,49,50,52,54,56,62,63,65,69,74-76]$; İnce et al. 2016. While this term is explained as a fundamental factor of cost of land, land topography, land ownership, and running/ maintenance cost in some reviewed papers $[70,75]$, it is frequently described as a total factor of land and construction costs $[26,33,69]$.

The second vital criteria group concerns with demand conditions in hospital location selection analysis. In this group, three important subcriteria are mentioned [43, 45] as population quantity, population density, and population age scattering. The demand for the potential hospital is directly related to the area's population where it will be established. Thus, the demand in a large city is expected to be higher than in a rural area. Population density calculated as population per square meter is another crucial criterion that corresponds to the hospital scale and type. The type of disease (acute, chronic, and so on) in the potential hospital is related to distributing the population's age. For example, if there is a risk of cancer in most of the population living in that area, it would be appropriate to evaluate building a cancer hospital. Similar to the contributions of the earliest 
TABLE 2: The differences between the six MCDM environments used or likely to be used in hospital location selection.

\begin{tabular}{|c|c|c|c|c|}
\hline $\begin{array}{l}\text { Type of MCDM } \\
\text { environment }\end{array}$ & Data type & $\begin{array}{c}\text { Considers information } \\
\text { uncertainty }\end{array}$ & $\begin{array}{l}\text { Measure the degree of membership and } \\
\text { nonmembership }\end{array}$ & $\begin{array}{l}\text { Amount of uncertainty } \\
\text { information covered }\end{array}$ \\
\hline Classical MCDM & Crisp & No & No & Low \\
\hline Grey MCDM & $\begin{array}{c}\text { Grey } \\
\text { numbers }\end{array}$ & Yes & No & Low \\
\hline General fuzzy MCDM & $\begin{array}{c}\text { Fuzzy } \\
\text { numbers }\end{array}$ & Yes & No & Low \\
\hline $\begin{array}{l}\text { Intuitionistic fuzzy } \\
\text { MCDM }\end{array}$ & $\begin{array}{c}\text { Fuzzy } \\
\text { numbers }\end{array}$ & Yes & Yes & Low \\
\hline $\begin{array}{l}\text { Pythagorean fuzzy } \\
\text { MCDM }\end{array}$ & $\begin{array}{c}\text { Fuzzy } \\
\text { numbers }\end{array}$ & Yes & Yes & Medium \\
\hline $\begin{array}{l}\text { Fermatean fuzzy } \\
\text { MCDM }\end{array}$ & $\begin{array}{c}\text { Fuzzy } \\
\text { numbers }\end{array}$ & Yes & Yes & High \\
\hline
\end{tabular}

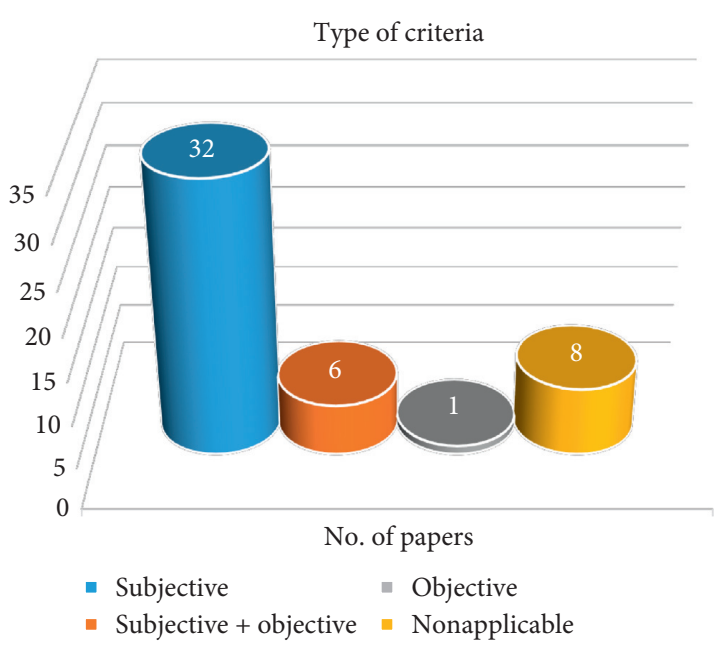

Figure 6: Distribution of papers in terms of the type of criteria.

two works [43, 45] and Lin and Tsai [37], many studies consider a demand-based main criterion on hospital location selection problem $[1,26,37,38,42,44,50,64,69]$. In a study by Şahin et al. [1], two additional criteria are attached to the criteria pool named as income and possibility of population change. Çelikbilek [44], Khotbehsara and Safari [68], Khaksefidi and Miri [36], Vahidnia et al. [56], Soltani and Marandi [55], Soltani et al. [76], Abdullahi et al. [25], and Yuen [77] took into consideration merely "population density" as a demand criterion. A different subcriterion of "prospective population" is used in a study by Senvar et al. [39] and Adalı and Tuş [33]. As a creative subcriterion under the "population characteristics" main criterion, Kumar et al. [49] suggested four headings: education, earning/economy, the structure of the society, and health awareness. This is differentiated from the others in the literature. From this aspect, for future studies, scholars may pay more attention to these. In some reviewed papers, authors prefer to mention demand conditions under the name of "demographic structure/demographic infrastructure/demographics" [2, 33-35, 39].

The third criteria group is related to the firm strategy, structure, and rivalry. This group is investigated under three subcriteria as a management objective, competitor hospitals, and policymakers' attitude [37, 43, 45]. The management objective is associated with establishing a mission, vision, and policy statement for the management practices [42]. The rivalry among hospitals or competitor hospitals impacts a new hospital investment project and the location of the new hospital building. The policymakers' attitude affects the decision of possible hospital location. For example, the administrators, consultants, and architects may have different opinions towards management's style. And, this conjuncture is likely to affect the decision. Studies by Sahin et al. [1], Yuen [77], İnce et al. [74], and Organ and Tekin [54] considered "competitors" as the leading criterion group. They determined four subcriteria under this group named medical technology, total beds, units, and whole hospitals. In a study by Assad [26], a group called "administrative concerns" is mentioned regarding firm strategy, structure, and rivalry. It includes policymakers' attitudes and hospital personnel. Wibowo [64] suggested the organizational system's main criteria covering the subjective assessment of management's attitudes towards business practices and competitors. This is often determined by the management objective, the management's attitude towards competition from other hospitals, and policymakers' attitude towards the management style to achieve long-term success.

The fourth criteria group suggested by the owner of the first study on hospital location selection [45] is "related and supporting sectors." The existence of related and supporting sectors is an essential factor affecting location choice. It is evaluated on three subcriteria, including medical practices and the pharmaceutical sector, hospital management sector, and health sector $[43,50,51]$. As the equivalent of this criterion, main criterion group with different names is available in the literature such as "industries and educational institutions" [31], "supply chain sector" [42], "related industry" [1], "sector support" [69], "supporting industries" [64], "support" [72, 73], "medical suppliers" [44], and "existing healthcare centers" [76]. All of the terms mentioned above have the same meaning as Lin et al. [45] which is "relevant and supportive sectors."

The fifth group covers governmental policy efforts towards establishing hospitals to strengthen their competitiveness $[1,33,37,38,42,43,45,50,51,64]$. This group is investigated under three subcriteria, including qualifications 
TABle 3: The main criteria used in the selection of hospital location.

\begin{tabular}{|c|c|}
\hline Study & Main criteria \\
\hline Sharmin and Neema [31] & Existing hospitals, road, industries, educational institutions, water bodies \\
\hline Miç and Antmen [2] & $\begin{array}{c}\text { Demographic structure, investment costs, travel time and travel costs, environmental factors, } \\
\text { infrastructure, location }\end{array}$ \\
\hline Khotbehsara and Safari [68] & Compatibility, population density, principle of access radius \\
\hline Önüt et al. [42] & Factors, demand situation, government, competitors, supply chain sector, possibilities \\
\hline Baran [34] & $\begin{array}{c}\text { Investment costs, demographic structure, environmental factors, building location factors, building } \\
\text { properties }\end{array}$ \\
\hline Şahin et al. [1] & Competitors, demand factors, environmental conditions, accessibility, related industry, government \\
\hline Chiu and Tsai [69] & Demand, construction costs, transportation, sector support, future development \\
\hline Lin et al. [50] & $\begin{array}{l}\text { Service demand, investment cost, transportation convenience, competition situation, government } \\
\text { regulation, related and supporting industries }\end{array}$ \\
\hline Islam et al. [62] & Environment and safety, size, accessibility, cost-effectiveness, risk \\
\hline Assad [26] & Cost, demand, disaster risk, environment, administrative concerns, other \\
\hline Chatterjee [3] & Cost, population characteristics, location \\
\hline Dell'Ovo et al. [70] & Functional quality, location quality, environmental quality, economic aspect \\
\hline Kmail et al. [29] & $\begin{array}{c}\text { Land use, distance to existing hospitals, near main roads, distance to dumping sites, distance industrial } \\
\text { areas, elevation }\end{array}$ \\
\hline Lin and Tsai [37] & Factor conditions, government role, demand conditions, agglomeration effects \\
\hline Wibowo [64] & $\begin{array}{c}\text { Financial attractiveness, demand potential, organizational strategy, supporting industries, } \\
\text { government influence, marketing dynamics }\end{array}$ \\
\hline Mohammed et al. [71] & Urban factors, environmental factors, economic factors \\
\hline Kim et & Needs, capacity, support \\
\hline Eldemir and Onden [27] & Competition, accessibility, environment \\
\hline Çelikbilek [44] & $\begin{array}{l}\text { Building cost, population density, prospective population, distance to social centers, medical } \\
\text { suppliers, other institutions, easy access for ambulances, transportation, hospital demand at the } \\
\text { location, availability of parking lot }\end{array}$ \\
\hline İnce et al. [74] & $\begin{array}{l}\text { Building characteristics and location, environmental factors, demography, competitors, investment } \\
\text { costs }\end{array}$ \\
\hline Khaksefidi and Miri [36] & $\begin{array}{c}\text { Accidents, rate of population-dense, quality of road, distance from the center of the province, distance } \\
\text { from the two other cities, climate of area }\end{array}$ \\
\hline Kahraman et al. [35] & $\begin{array}{c}\text { Installation costs, closeness to the target area, environmental factors, demographic infrastructure, } \\
\text { transportation opportunities }\end{array}$ \\
\hline Sen $[52]$ & $\begin{array}{l}\text { Site conditions and surrounding, accessibility and traffic, patient/emergency access consideration, } \\
\text { cost, future considerations, nuisance }\end{array}$ \\
\hline Şen and Demiral [65] & $\begin{array}{l}\text { Site conditions and surrounding, accessibility and traffic, patient/emergency access consideration, } \\
\text { cost, future considerations, nuisance }\end{array}$ \\
\hline Rahir & Population, accessibility, road network, incompatibility, compatibility, land specifications \\
\hline Alesheikh [66] & Environment, city, road, hospital, contan \\
\hline Vahidnia e & Distance from arterial routes, travel time, contamination, land cost, population density \\
\hline Soltani and Marandi [55] & $\begin{array}{l}\text { Distance to arterials and significant roads, distance to other medical centers, population density, } \\
\text { parcel size }\end{array}$ \\
\hline Senvar et al. [39] & Cost, demographics, market conditions, business, transportation, workers, building structure \\
\hline Adalı and Tuş [33] & $\begin{array}{c}\text { Market conditions, cost, transportation, geological factors, land strategy, financial support by the } \\
\text { government, environment, demographics }\end{array}$ \\
\hline Mahı & Environment and safety, size, accessibility, cost-effectiveness, risk \\
\hline Lin and Tsai [38] & Factor conditions, government role, demand conditions, agglomeration effects \\
\hline Kumar et al. [49] & $\begin{array}{c}\text { Cost, proximity, population characteristics, availability of human resources, accessibility, } \\
\text { environment }\end{array}$ \\
\hline Chatterjee and Mukherjee [75] & Cost, population characteristics, location \\
\hline Lin et al. [45] & $\begin{array}{c}\text { Factor conditions, demand conditions, firm strategy structure rivalry, related and supported } \\
\text { industries, government, chance }\end{array}$ \\
\hline Wu et al. [43] & $\begin{array}{c}\text { Factor conditions, demand conditions, firm strategy structure rivalry, related and supported } \\
\text { industries, government, chance }\end{array}$ \\
\hline Ahmed et al. [67] & Environmental factors, urban factors, economic factors \\
\hline Soltani et al. [76] & $\begin{array}{c}\text { Transportation network, existing healthcare centers, land use, population density, distance from } \\
\text { industrial centers, existing fire stations, urban green spaces }\end{array}$ \\
\hline Abdullahi et al. [25] & Technical issues, environmental issues, socioeconomic issues \\
\hline Organ and Tekin [54] & $\begin{array}{l}\text { Intensity of target audience, proximity to residential units, proximity to noise sources, centrality, } \\
\text { accessibility, personnel transportation, distance to competitors, competitors' effectiveness, } \\
\text { infrastructure competence, cost of building regulation, cost of environmental law, detectability }\end{array}$ \\
\hline
\end{tabular}


TABLE 3: Continued.

\begin{tabular}{lc}
\hline Study & Main criteria \\
\hline $\begin{array}{l}\text { Shahbandarzadeh and } \\
\text { Ghorbanpour [51] }\end{array}$ & Factor conditions, geographical conditions, related and supported industries, government \\
Yuen [77] & $\begin{array}{c}\text { Population density, land cost, community support, transportation convenience, competing hospitals, } \\
\text { environmental favor }\end{array}$ \\
Kaveh et al. [28] & $\begin{array}{c}\text { Distance from the existing hospitals, distance from fire stations, distance from population centers, } \\
\text { distance from road and street network, distance from green spaces and parks, distance from strong } \\
\text { power lines, distance from fault } \\
\text { Zolfani et al. [53] }\end{array}$ \\
Technological, economic, social
\end{tabular}

of the hospital's establishment and the regulations of the established standard, efforts to promote a medical network, and promulgating tasks that require a hospital's assessment $[37,43,45]$. In a study by Önüt et al. [42] and Şahin et al. [1], this group consists of incentives, legislation, policies, and tax.

The final group is named as chance. It includes three subcriteria: sharp change in demand in the market, unusual fluctuations in production costs (e.g., bullwhip effect), and sudden change in the financial market and exchange rate. For example, the Covid-19 disease, which has recently emerged in China and has caused a major epidemic worldwide, has caused a sudden fluctuation in demand, directly affecting new hospital investments. This main criteria group has been handled by many scholars with different definitions and scope. For example, while a criterion heading of "Risk" is used in a study by Islam et al. [62] and Mahmud et al. [71], a term of "Disaster risk" is mentioned in a study by Assad [26]. However, the risk concept in the study by Islam et al. [62] and Mahmud et al. [63] is quite different from the meaning explained here. They mean risk as a function of land risk, construction risk, and time frame and delivery speed. Some papers consider this a change in the market or market dynamics [33, 39, 64].

Apart from all these, another essential criterion group is the evaluations about the distance of the location to some points. In this context, subcriteria such as distance to existing hospitals, proximity to main roads, distance to dumping areas $[28,29]$, distance to industrial areas $[29,76]$, distance to social centers, distance to medical suppliers, distance to other governmental buildings, easy access to ambulances $[28,44]$, distance to the city center, distance to other neighboring cities [36], distance to main arteries [56], distance to arteries and main roads, distance to other medical centers $[54,55]$, proximity to residential units, and proximity to noise sources [54] are emphasized in the reviewed papers. In the study of Kaveh et al. [28], the selection criteria are directly related with distance. Seven criteria named as distance from the existing hospitals, distance from fire stations, distance from population centers, distance from road and street network, distance from green spaces and parks, distance from strong power lines, and distance from fault are used.

Moradian et al. [9] studied the risk criteria in hospital site selection and performed a systematic literature review. However, the scoping and time period of this review is limited. They focus only on selection criteria and their classification of the studies published till 2017. That study does not include a comprehensive discussion on applied MCDM methods and their extensions. The criteria classification of Moradian et al. [9]'s review is executed under four groups as cost concerns, demand concerns, disaster risk concerns, and environmental concerns. In the light of all discussions as mentioned above and inferences from the reviewed 47 papers, we can suggest a generic hierarchical framework of the hospital location selection problem as presented in Figure 7. We believe this framework can benefit the scholars who will study the MCDM problems of hospital location selection $[74,78]$.

3.7. Open Areas and Suggestions for Future Work. The point to be noted here is that the importance of the "location selection problem" increases due to the need for rapid establishment of hospital investments during critical and disaster events. New criteria should be added to the hierarchical framework for hospital location selection in such disastrous situations, as explained in Figure 7. In this framework, some of them are mentioned within the main criterion of "Chance" and within the main criterion of "Related and supporting sectors." A patient influx in demand, variability in drug, equipment, and device costs, rapid change of economic indicators (financial bottlenecks that may be encountered in global pandemic conditions), and difficulties to be experienced in the pharmaceutical, material, equipment supply chain, and supporting sectors can be counted as new criteria that will directly affect new hospital investments.

From a methodological perspective, this problem is generally addressed through the MCDM concept and the methods created by integrating this concept with fuzzy logic. Apart from that, models supported with GIS have been included in the literature. In this context, it is seen that the innovations in the field of MCDM have not yet taken place at the desired level for this problem. It is expected that methods such as BWM that provide less pairwise comparison and a more consistent subjective evaluation can be used more in obtaining the relative importance weights of the hospital location criteria in future studies. However, at the stage of determining alternative locations according to weighted criteria, the newly proposed fuzzy set versions (such as Pythagorean fuzzy set, Fermatean fuzzy set, and q-rung orthopair fuzzy set) should be preferred more frequently. Well-known and applied MCDM methods such as 


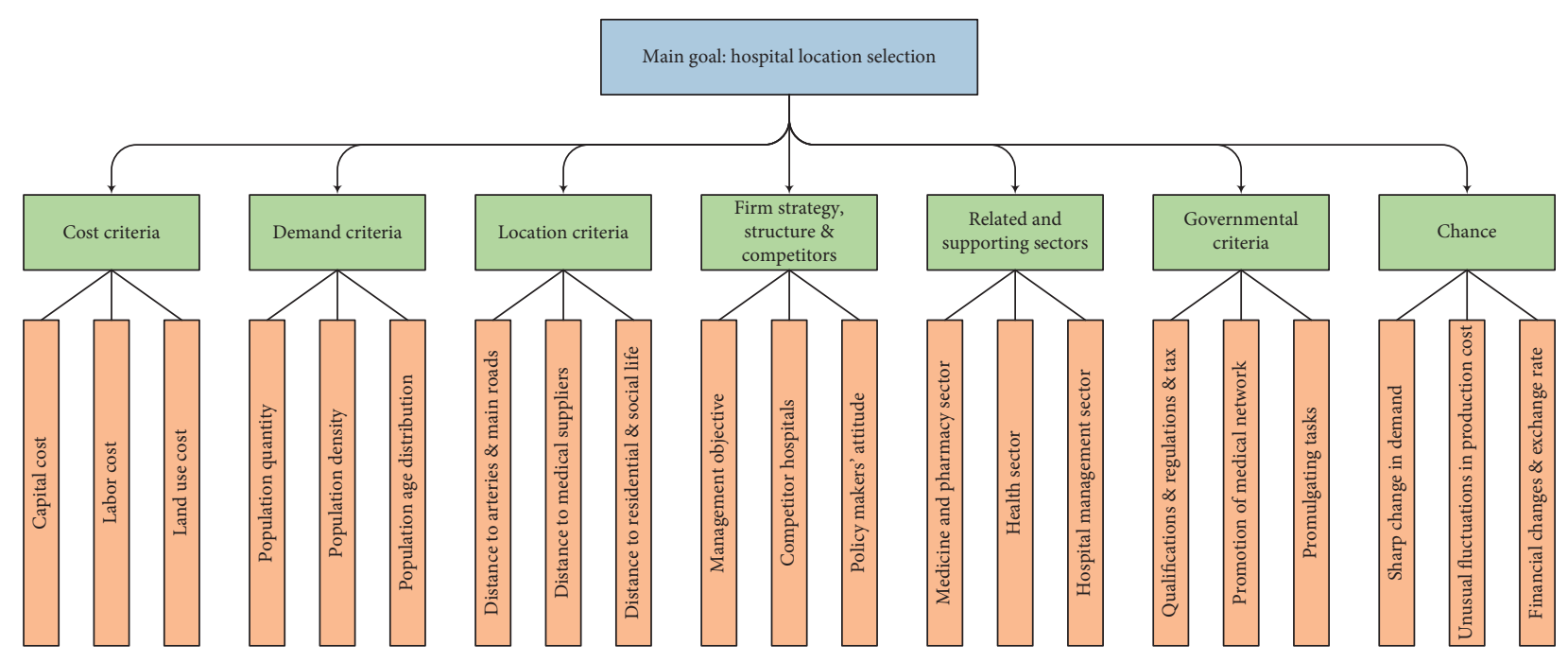

Figure 7: Generic framework on the hospital location selection criteria.

PROMETHEE, DEMATEL, MAIRCA, MULTIMOORA, and TODIM can be used in this problem with these improved fuzzy set versions. The conventional MCDM methods (like AHP, TOPSIS, and VIKOR) do not consider data/information uncertainty, converting experts' judgments into a crisp value. The general and extended fuzzy MCDM reflects the uncertainty of experts' assessment environment but does not measure the degree of membership and nonmembership of the evaluated events simultaneously. In this case, intuitionistic, Pythagorean, and Fermatean fuzzy MCDM can gain importance and address and solve the problem by providing low, medium, and high uncertainty information levels, respectively.

\section{Conclusion}

The hospital location selection problem occupies an essential place among general facility location problems. Hospitals are not ordinary facilities. They are facilities established for a vital need that manage many complex processes designed for patients to receive comprehensive health care. Therefore, while making an investment decision regarding these facilities, determining the appropriate location makes it necessary to consider many different criteria. In this context, such a problem can be easily modeled as an MCDM concept and the most suitable alternative can be determined.

In this paper, a systematic and state-of-the-art review of 47 papers on hospital location selection is presented. All papers were classified by publication trend, published journal, country of origin, methods used to select the location, MCDM environment, type of decision criteria, and the main criteria in the selection process. The ultimate goal is to provide researchers and practitioners with a useful guide on the topic. The following are pointed out in the statistical figures from the retrieved articles. (1) Usage of AHP and GIS-based MCDM models is following an increasing trend compared with others (ones constructed by ANP, TOPSIS, and so on). (2) A scattered distribution is available in the published journals. (3) Turkey ranks first by accounting for almost $28 \%$ of all papers related to hospital location selection models. (4) Classical and general fuzzy MCDM concepts are the two most preferred environments based on the data in crisp and fuzzy numbers. Also, fuzzy triangular numbers are the most used fuzzy set version. The newly developed versions (intuitionistic, Pythagorean, and Fermatean) under fuzzy logic theory are suitable for this field. They are extremely good in terms of the amount of uncertainty information covered. (5) Researchers mostly prefer cost, demand, environment, population, government, competition on the market, and distance to essential locations as main selection criteria. Given the Covid-19 pandemic results, where the health sector is currently in a great struggle, it is clear that the new hospital's location decisions, field hospital, or pandemic hospital investments should be made quickly and reliably. This reinforces the conclusion that a possible rapid demand situation scenario (such as a pandemic, natural, and handmade aphids) that emerge from this study and has not been mentioned by most of the researchers in the review will play a significant role in the location selection decision. We expect and observe that, in the future, the number of applications and approaches related to hospital location selection will rise in the literature.

The following suggestions can be enriched by the following future research. This study handles the problem of hospital location selection from the perspective of MCDM in the literature. Researchers could consider different topics regarding healthcare domain such as hospital service quality evaluation, hospital demand forecasting, and hospital facility layout design. These rarely considered topics with/without MCDM concepts can be further studied. A new topic of future research is the development of MCDM approaches for disaster time location selection problem. This type of problem may vary from the normal time problem in terms of selection criteria. Various risk criteria may exist related to the disaster type. 


\section{Nomenclature}

\begin{tabular}{|c|c|}
\hline ABM: & Agent-based modeling \\
\hline AHP: & Analytic hierarchy process \\
\hline ANN: & Artificial neural network \\
\hline ANP: & Analytic network process \\
\hline ARAS-G: & $\begin{array}{l}\text { Additive Ratio Assessment Method with } \\
\text { Grey Values }\end{array}$ \\
\hline CoCoSo: & Combined compromise solution \\
\hline CODAS: & Combinative distance-based assessment \\
\hline CRITIC: & $\begin{array}{l}\text { CRiteria importance through } \\
\text { intercriteria correlation }\end{array}$ \\
\hline D-AHP: & Delphi analytic hierarchy process \\
\hline DF-AHP: & Delphi fuzzy analytic hierarchy process \\
\hline EDAS: & $\begin{array}{l}\text { Evaluation based on distance from } \\
\text { average solution }\end{array}$ \\
\hline ELECTRE: & $\begin{array}{l}\text { ELimination Et Choix Traduisant la } \\
\text { Realité }\end{array}$ \\
\hline F-AHP: & Fuzzy analytic hierarchy process \\
\hline F-ANP: & Fuzzy analytic network process \\
\hline F-ELECTRE: & $\begin{array}{l}\text { Fuzzy ELimination Et Choix Traduisant } \\
\text { la Realité }\end{array}$ \\
\hline F-MCDM: & Fuzzy Multicriteria decision-making \\
\hline F-SAW: & Fuzzy simple additive weighting \\
\hline F-TOPSIS: & $\begin{array}{l}\text { Fuzzy technique for order preference by } \\
\text { similarity to ideal solution }\end{array}$ \\
\hline GA: & Genetic algorithm \\
\hline GIS: & Geographic information systems \\
\hline GRA: & Grey relational analysis \\
\hline HF-TOPSIS: & $\begin{array}{l}\text { Hesitant fuzzy technique for order } \\
\text { preference by similarity to ideal solution }\end{array}$ \\
\hline P-CNP: & Primitive cognitive network process \\
\hline SAW: & Simple additive weighting \\
\hline SF-TOPSIS: & $\begin{array}{l}\text { Spherical fuzzy technique for order } \\
\text { preference by similarity to ideal solution }\end{array}$ \\
\hline TOPSIS: & $\begin{array}{l}\text { Technique for order preference by } \\
\text { similarity to ideal solution }\end{array}$ \\
\hline VIKOR: & VlseKriterijumska Optimizacija I \\
\hline & Kompromisno Resenje \\
\hline BWM: & Best and worst method \\
\hline PROMETHEE: & $\begin{array}{l}\text { Preference ranking organization method } \\
\text { for enrichment evaluations }\end{array}$ \\
\hline PSO: & Particle swarm optimization \\
\hline DEMATEL: & $\begin{array}{l}\text { Decision-making trial and evaluation } \\
\text { laboratory }\end{array}$ \\
\hline TODIM: & $\begin{array}{l}\text { Interactive and multiple attribute } \\
\text { decision-making }\end{array}$ \\
\hline MULTIMOORA: & $\begin{array}{l}\text { Multiobjective optimization by ratio } \\
\text { analysis }\end{array}$ \\
\hline MAIRCA: & $\begin{array}{l}\text { Multiattribute ideal real comparative } \\
\text { analysis. }\end{array}$ \\
\hline
\end{tabular}

\section{Conflicts of Interest}

The authors declare that they have no known conflicts of interest or personal relationships that could have appeared to influence the work reported in this paper. There are no conflicts of interest between authors.

\section{References}

[1] T. Şahin, S. Ocak, and M. Top, "Analytic hierarchy process for hospital site selection," Health Policy and Technology, vol. 8, no. 1, pp. 42-50, 2019.

[2] P. Miç and Z. F. Antmen, "A healthcare facility location selection problem with fuzzy TOPSIS method for a regional hospital," Avrupa Bilim Ve Teknoloji Dergisi, no. 16, pp. 750-757, 2019.

[3] D. Chatterjee, "Can fuzzy extension of Delphi-analytical hierarchy process improve hospital site selection?" International Journal of Intercultural Information Management, vol. 4, no. 2-3, pp. 113-128, 2014.

[4] A. S. Tareq, O. S. Albahri, A. A. Zaidan et al., "Based multiple heterogeneous wearable sensors: a smart real-time health monitoring structured for hospitals distributor," IEEE Access, vol. 7, pp. 37269-37323.

[5] O. S. Albahri, A. S. Albahri, A. A. Zaidan et al., "Fault-tolerant mHealth framework in the context of IoT-based real-time wearable health data sensors," IEEE Access, vol. 7, pp. 50052-50080.

[6] M. Gul and M. Yucesan, "Hospital preparedness assessment against COVID-19 pandemic: a case study in Turkish tertiary healthcare services," Mathematical Problems in Engineering, vol. 2021, Article ID 2931219, , 2020.

[7] M. Ortiz-Barrios, M. Gul, P. López-Meza, M. Yucesan, and E. Navarro-Jiménez, "Evaluation of hospital disaster preparedness by a multi-criteria decision making approach: the case of Turkish hospitals," International Journal of Disaster Risk Reduction, vol. 49, Article ID 101748, 2020.

[8] M. Yucesan and M. Gul, "Hospital service quality evaluation: an integrated model based on Pythagorean fuzzy AHP and fuzzy TOPSIS," Soft Computing, vol. 24, no. 5, pp. 3237-3255, 2020.

[9] M. J. Moradian, A. Ardalan, A. Nejati, A. D. Boloorani, A. Akbarisari, and B. Rastegarfar, "Risk criteria in hospital site selection: a systematic review," PLoS Currents, vol. 9, 2017.

[10] H. Z. Al Garni and A. Awasthi, "Solar PV power plants site selection," Advances in Renewable Energies and Power Technologies, vol. 1, pp. 57-75, 2018.

[11] C. Kahraman, D. Ruan, and I. Doğan, "Fuzzy group decisionmaking for facility location selection," Information Sciences, vol. 157, pp. 135-153, 2003.

[12] Y. Ma, W. Xu, L. Qin, and X. Zhao, "Site selection models in natural disaster shelters: a review," Sustainability, vol. 11, no. 2, p. 399, 2019.

[13] M. Shao, Z. Han, J. Sun, C. Xiao, S. Zhang, and Y. Zhao, “A review of multi-criteria decision making applications for renewable energy site selection," Renewable Energy, vol. 157, pp. 377-403, 2020.

[14] A. Soltani, A. Ardalan, A. Darvishi Boloorani, A. Haghdoost, and M. J. Hosseinzadeh-Attar, "Site selection criteria for sheltering after earthquakes: a systematic review," PLoS Currents, vol. 6, 2014.

[15] J. Y. L. Yap, C. C. Ho, and C. Y. Ting, “A systematic review of the applications of multi-criteria decision-making methods in site selection problems," Built Environment Project and Asset Management, vol. 9, no. 4, pp. 548-563, 2019.

[16] A. Alamoodi, B. Zaidan, A. Zaidan et al., "Sentiment analysis and its applications in fighting COVID-19 and infectious diseases: a systematic review," Expert Systems with Applications, Article ID 114155, 2020.

[17] A. S. Alamoodi, J. K. Alwan, Z. K. Taha et al., "IoT-based telemedicine for disease prevention and health promotion: 
state-of-the-Art," Journal of Network and Computer Applications, vol. 173, Article ID 102873, 2020.

[18] A. S. Albahri, A. A. Zaidan, O. S. Albahri, B. B. Zaidan, and M. A. Alsalem, "Real-time fault-tolerant mHealth system: comprehensive review of healthcare services, opens issues, challenges and methodological aspects," Journal of Medical Systems, vol. 42, no. 8, p. 137, 2018.

[19] O. S. Albahri, A. S. Albahri, K. I. Mohammed et al., "Systematic review of real-time remote health monitoring system in triage and priority-based sensor technology: taxonomy, open challenges, motivation and recommendations," Journal of Medical Systems, vol. 42, no. 5, p. 80, 2018.

[20] O. S. Nidhal, A. A. Zaidan, B. B. Zaidan, M. Hashim, A. S. Albahri, and M. A. Alsalem, "Real-time remote healthmonitoring systems in a medical centre: a review of the provision of healthcare services-based body sensor information, open challenges and methodological aspects," Journal of Medical Systems, vol. 42, no. 9, p. 164, 2018.

[21] L.-X. Hou, R. Liu, H.-C. Liu, and S. Jiang, "Two decades on human reliability analysis: a bibliometric analysis and literature review," Annals of Nuclear Energy, vol. 151, Article ID 107969, 2021.

[22] H. C. Liu, L. J. Zhang, Y. J. Ping, and L. Wang, "Failure mode and effects analysis for proactive healthcare risk evaluation: a systematic literature review," Journal of Evaluation in Clinical Practice, vol. 26, no. 4, pp. 1320-1337, 2020.

[23] L. J. Zhang, R. Liu, H. C. Liu, and H. Shi, "Green supplier evaluation and selections: a state-of-the-art literature review of models, methods, and applications," Mathematical Problems in Engineering, vol. 2020, Article ID 1783421, , 2020.

[24] M. Parsa Moghadam, M. Yazdani, A. Seyyedin, and M. Pashazadeh, "Optimal site selection of urban hospitals using GIS software in Ardabil City," Journal of Ardabil University of Medical Sciences, vol. 16, no. 4, pp. 374-388, 2017.

[25] S. Abdullahi, A. R. B. Mahmud, and B. Pradhan, "Spatial modelling of site suitability assessment for hospitals using geographical information system-based multicriteria approach at Qazvin city, Iran," Geocarto International, vol. 29, no. 2, pp. 164-184, 2014.

[26] C. A. R. Assad, "Building GIS framework based on multi criteria analysis for hospital site selection in developing countries," International Journal of Computer Techniques, vol. 6, no. 4, pp. 1-6, 2019.

[27] F. Eldemir and I. Onden, "Geographical information systems and multicriteria decisions integration approach for hospital location selection," International Journal of Information Technology \& Decision Making, vol. 15, no. 5, pp. 975-997, 2016.

[28] M. Kaveh, M. Kaveh, M. S. Mesgari, and R. S. Paland, "Multiple criteria decision-making for hospital location-allocation based on improved genetic algorithm," Applied Geomatics, vol. 12, no. 1, pp. 1-16, 2020.

[29] A. Kmail, J. Jubran, W. Sabbah, and P. Jenin, "Coupling GISbased MCA and AHP techniques for hospital site selection," International Journal of Computer Science and Information Security (IJCSIS), vol. 15, no. 12, 2017.

[30] F. Rahimi, A. Goli, and R. Rezaee, "Hospital location-allocation in Shiraz using geographical information system (GIS)," Shiraz E-Medical Journal, vol. 18, no. 8, 2017.

[31] N. Sharmin and M. N. Neema, "A GIS-based multi-criteria analysis to site appropriate locations of hospitals in Dhaka City," Hospital, vol. 8, pp. 1-37, 2013.
[32] I. Zandi and P. Pahlavani, Spatial Modeling and Prioritization of Potential Areas for Determining Location of Hospitals by a GIS-Based Multi-Criteria Decision Making Analyses: A Case Study: The 5th Region of the Tehran. Town and Country Planning, 2021.

[33] E. A. Adalı and A. Tuş, "Hospital site selection with distancebased multi-criteria decision-making methods," International Journal of Healthcare Management, pp. 1-11, 2019.

[34] E. Baran, "An innovative fuzzy TOPSIS method to determine the location of A new hospital," International Journal of Engineering Science and Application, vol. 2, no. 4, pp. 133-136, 2018.

[35] C. Kahraman, F. K. Gundogdu, S. C. Onar, and B. Oztaysi, "Hospital location selection using spherical fuzzy TOPSIS," in Proceedings of the 2019 Conference of the International Fuzzy Systems Association and the European Society for Fuzzy Logic and Technology (EUSFLAT 2019), Prague, Czech Republic, August 2019.

[36] M. Khaksefidi and M. Miri, "Hospital location in the Southern Fars province by using multi criteria decision making techniques," European Online Journal of Natural and Social Sciences: Proceedings, vol. 4, no. 3, p. 638, 2016.

[37] C.-T. Lin and M.-C. Tsai, "Development of an expert selection system to choose ideal cities for medical service ventures," Expert Systems with Applications, vol. 36, no. 2, pp. 22662274, 2009.

[38] C.-T. Lin and M.-C. Tsai, "Location choice for direct foreign investment in new hospitals in China by using ANP and TOPSIS," Quality \& Quantity, vol. 44, no. 2, pp. 375-390, 2010.

[39] O. Senvar, I. Otay, and E. Bolturk, "Hospital site selection via hesitant fuzzy TOPSIS,” IFAC-PapersOnLine, vol. 49, no. 12, pp. 1140-1145, 2016.

[40] C. L. Hwang and K. P. Yoon, Multiple Attribute Decision Making: An Introduction, SAGE publications, Thousand Oaks, CA, USA, 1995.

[41] N. E. Oz, S. Mete, F. Serin, and M. Gul, "Risk assessment for clearing and grading process of a natural gas pipeline project: an extended TOPSIS model with Pythagorean fuzzy sets for prioritizing hazards," Human and Ecological Risk Assessment: An International Journal, vol. 25, no. 6, pp. 1615-1632, 2019.

[42] S. Önüt, U. R. Tuzkaya, and B. Kemer, "An analytical network process approach to the choice of hospital location," Journal of Engineering and Natural Sciences, vol. 25, no. 4, pp. 367-379, 2008.

[43] C.-R. Wu, C.-T. Lin, and H.-C. Chen, "Optimal selection of location for Taiwanese hospitals to ensure a competitive advantage by using the analytic hierarchy process and sensitivity analysis," Building and Environment, vol. 42, no. 3, pp. 1431-1444, 2007.

[44] Y. Çelikbilek, "Group decision making for hospital location selection using VIKOR under fuzzy environment," Istanbul Gelisim University Journal of Health Sciences, vol. 5, pp. 435-450, 2018.

[45] C. T. Lin, C. R. Wu, and H. C. Chen, "Selecting the location of hospitals in taiwan to ensure a competitive advantage via GRA," Journal of Grey System, vol. 18, no. 3, 2006.

[46] S. Wang, G. Wei, J. Wu, C. Wei, and Y. Guo, "Model for selection of hospital constructions with probabilistic linguistic GRP method," Journal of Intelligent \& Fuzzy Systems, vol. 40, no. 1, pp. 1245-1259, 2021.

[47] S. Opricovic, Multicriteria optimization of civil engineering systems, PhD Thesis, Faculty of Civil Engineering, Belgrade, Serbia, 1998. 
[48] M. Gul, E. Celik, N. Aydin, A. T. Gumus, and A. F. Guneri, "A state of the art literature review of VIKOR and its fuzzy extensions on applications," Applied Soft Computing, vol. 46, pp. 60-89, 2016.

[49] P. Kumar, R. K. Singh, and P. Sinha, "Optimal site selection for a hospital using a fuzzy extended ELECTRE approach," Journal of Management Analytics, vol. 3, no. 2, pp. 115-135, 2016.

[50] H. Y. Lin, C. J. Liao, and Y. H. Chang, "Applying fuzzy simple additive weighting system to health examination institution location selection," in Proceedings of the 2010 IEEE 17Th International Conference on Industrial Engineering and Engineering Management, pp. 646-650, Xiamen, China, October 2010.

[51] H. Shahbandarzadeh and A. Ghorbanpour, "The applying ISM/FANP approach for appropriate location selection of health centers," Iranian Journal of Management Studies, vol. 4, no. 2, pp. 5-28, 2011.

[52] H. Sen, "Hospital location selection with ARAS-G," The Eurasia Proceedings of Science, Technology, Engineering \& Mathematics, vol. 1, pp. 359-365, 2017.

[53] S. Hashemkhani Zolfani, M. Yazdani, A. Ebadi Torkayesh, and A. Derakhti, "Application of a gray-based decision support framework for location selection of a temporary hospital during COVID-19 pandemic," Symmetry, vol. 12, no. 6, p. 886, 2020.

[54] A. Organ and B. Tekin, "Șehï Hastanesii Kuruluş Yeri Seçimi Için Gri Illişkisel Analiz Yaklaşimi: Denizlli Ili Örneği," Adnan Menderes Üniversitesi Sosyal Bilimler Enstitüsü Dergisi, vol. 4, no. 3, pp. 256-278, 2017, in Turkish.

[55] A. Soltani and I. Marandi, "Hospital site selection using twostage fuzzy multi-criteria decision making process," Journal of Urban and Environmental Engineering, vol. 5, no. 1, pp. 3243, 2011.

[56] M. H. Vahidnia, A. A. Alesheikh, and A. Alimohammadi, "Hospital site selection using fuzzy AHP and its derivatives," Journal of Environmental Management, vol. 90, no. 10, pp. 3048-3056, 2009.

[57] J. Rezaei, "Best-worst multi-criteria decision-making method," Omega, vol. 53, pp. 49-57, 2015.

[58] S. Guo and H. Zhao, "Fuzzy best-worst multi-criteria decision-making method and its applications," KnowledgeBased Systems, vol. 121, pp. 23-31, 2017.

[59] X. Mi, M. Tang, H. Liao, W. Shen, and B. Lev, "The state-of-the-art survey on integrations and applications of the best worst method in decision making: why, what, what for and what's next?" Omega, vol. 87, pp. 205-225, 2019.

[60] M. Yucesan and M. Gul, "Failure prioritization and control using the neutrosophic best and worst method," Granular Computing, pp. 1-15, 2019.

[61] M. Yucesan, S. Mete, F. Serin, E. Celik, and M. Gul, "An integrated best-worst and interval type-2 fuzzy TOPSIS methodology for green supplier selection," Mathematics, vol. 7, no. 2, p. 182, 2019.

[62] M. M. Islam, T. Mahmud, and M. S. Hossain, "Belief-rule-based intelligent decision system to select hospital location," Indonesian Journal of Electrical Engineering and Computer Science, vol. 1, no. 3, pp. 607-618, 2016.

[63] T. Mahmud, J. Sikder, and S. Tripura, "Knowledge-based decision support system to select hospital location," IOSR Journal of Computer Engineering, vol. 20, no. 3, pp. 39-47, 2018.

[64] S. Wibowo, "Evaluating and selecting hospital locations using fuzzy multicriteria decision making," Asian Journal of
Management Science and Applications, vol. 1, no. 3, pp. 278-291, 2014.

[65] H. Şen and M. F. Demiral, "Hospital location selection with grey system theory," European Journal of Economics and Business Studies, vol. 2, no. 2, pp. 66-79, 2016.

[66] S. Behzadi and A. A. Alesheikh, "Hospital site selection using a BDI agent model," International Journal of Geography and Geology, vol. 2, no. 4, p. 36, 2013.

[67] A. H. Ahmed, H. Mahmoud, and A. M. M. Aly, "Site suitability evaluation for sustainable distribution of hospital using spatial information technologies and AHP: a case study of Upper Egypt, Aswan city," Journal of Geographic Information System, vol. 8, no. 5, pp. 578-594, 2016.

[68] E. M. Khotbehsara and H. Safari, "A systematic review of affective factors on locating Specialized hospitals," Civil Engineering Journal, vol. 4, no. 9, pp. 2210-2217, 2018.

[69] J. E. Chiu and H. H. Tsai, "Applying analytic hierarchy process to select optimal expansion of hospital location: the case of a regional teaching hospital in Yunlin," in Proceedings of the 2013 10th International Conference on Service Systems and Service Management, pp. 603-606, Hong Kong, China, July 2013.

[70] M. Dell'Ovo, S. Capolongo, and A. Oppio, "Combining spatial analysis with MCDA for the siting of healthcare facilities," Land Use Policy, vol. 76, pp. 634-644, 2018.

[71] H. A. Mohammed, M. N. Ahmed, and A. J. Alsaad, "Evaluation of sustainable site selection using analytical hierarchy process for hospitals: Karbala city as a case study," International Journal of Engineering \& Technology, vol. 7, no. 4, pp. 347-350, 2018.

[72] J. I. Kim, J. Ruza, C. Kam, and S. Ng, "Evidence-based analyses of hospital site selection for the aging population in Dallas, Texas," in Proceedings of the ICSDEC 2012: Developing the Frontier of Sustainable Design, Engineering, and Construction, pp. 286-293, Fort Worth, TX, USA, 2013.

[73] J. Kim, D. Senaratna, J. Ruza, C. Kam, and S. Ng, "Feasibility study on an evidence-based decision-support system for hospital site selection for an aging population," Sustainability, vol. 7, no. 3, pp. 2730-2744, 2015.

[74] Ö. İnce, N. Bedir, and T. Eren, "Hastane Kuruluş Yeri Seçimi probleminin AHP ile Modellenmesi: tuzla İlçesi Uygulaması," Gazi Sağlık Bilimleri Dergisi, vol. 1, no. 3, pp. 8-21, 2016, in Turkish.

[75] D. Chatterjee and B. Mukherjee, "Potential hospital location selection using AHP: a study in rural India," International Journal of Computer Applications, vol. 71, no. 17, 2013.

[76] A. Soltani, R. B. Inaloo, M. Rezaei, F. Shaer, and M. A. Riyabi, "Spatial analysis and urban land use planning emphasising hospital site selection: a case study of Isfahan city," Bulletin of Geography. Socio-Economic Series, vol. 43, no. 43, pp. 71-89, 2019.

[77] K. K. F. Yuen, "Using the primitive cognitive network process for location analysis: comparisons with the analytic hierarchy process," Journal of Applied Operational Research, vol. 4, no. 4, pp. 194-202, 2012.

[78] F. K. Gündoğdu and C. Kahraman, "A novel fuzzy TOPSIS method using emerging interval-valued spherical fuzzy sets," Engineering Applications of Artificial Intelligence, vol. 85, pp. 307-323, 2019. 